\title{
Influence of Adaptive Power System Stabilizer on the Transient and Dynamic Performance of a Multimachine System
}

\author{
F.A. Khalifa*
}

W. Sabry**

\begin{abstract}
:
This paper presents a power system stabilizer (PSS) for improving the performance of a multimachine system when the system is subjected to different types of disturbances. An adaptive proportional-plus-derivative-plus-integral (PID) PSS is proposed in this paper. In this technique, the controller parameters (proportional, integral, and derivative gains) are not fixed but they are varying according to the system operating conditions. The derivative of power angle, error in output power, terminal voltage, and error in power angle are selected to be the input signals to the proposed stabilizer. A weighting factors are assigned to these signals to obtain the best performance characteristics of each machine. The obtained computer results from simulation study are compared with those of a conventional lead-lag stabilizer.
\end{abstract}

* Ass. Prof., Dept. of Electrical Power and Energy, Military Technical College, Cairo, Egypt.

** Ass. Teacher, Dept., of Electrical Power and Energy, Military Technical College, Cairo, Egypt. 


\section{1- Introduction :}

The application of PSS for improving the dynamic stability of large scale power system has been under extensive studies for many years [1-3]. The conventional PID controllers are the most widely used control strategy in these studies. These controllers are often poorly tuned and their gain settings are usually fixed at a certain set of values which are determined based on a particular operating point.

Adaptive control algorithm can be a good solution to such problems. They have the ability to track the system operating conditions and compute in real time the controller parameters according to the changes in the operating conditions of the process [4-6]. Recently, self-tuning controllers are introduced as power system stabilizers to enhance the dynamic stability of synchronous generators [7-8]. In this control technique, the parameters of the controller are not fixed but varying according to the system operating conditions.

In this paper, the performance characteristics of a multimachine power system when it is equipped with a self-tuning PID-PSS is investigated and discussed. The results obtained from digital simulation show that the proposed PSS can be used in multimachine power systems and provides good control performance.

\section{2- The System Model :}

The system considered in this paper is composed of three synchronous generators together with the loads and transmission network as shown in Fig.1. [3].

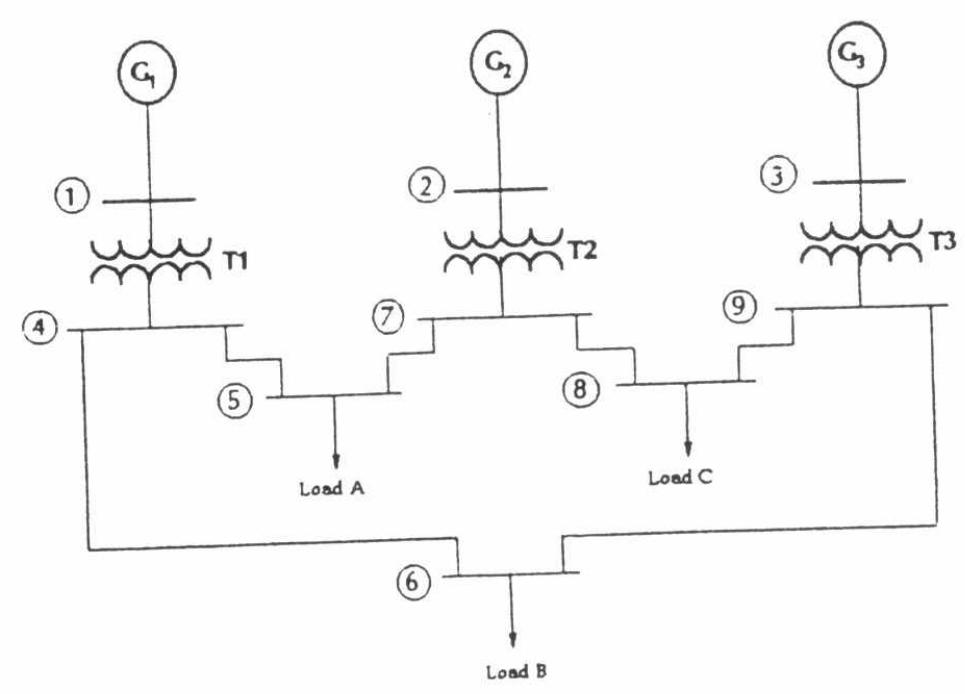

Fig.1 A multimachine power system model 
Each generator is provided with a static type 1-S exciter. The mathematical model of each generator is derived using the equations of the two axis model described in [3]. A description of the mathematical model of the power system under study together with the excitation system mathematical model are given in Appendix A.

The system data are as follows :

Generators (reactances in p.u. to 100 MVA base) :

\begin{tabular}{|l|c|c|c|}
\hline \multicolumn{1}{|c|}{ Generator } & $\mathbf{1}$ & $\mathbf{2}$ & $\mathbf{3}$ \\
\hline Rated MVA & 247.5 & 192 & 128 \\
Ratted KV & 16.5 & 18 & 13.8 \\
$\mathrm{H}$ & 23.64 & 6.4 & 3.01 \\
Power factor & 1.0 & 0.85 & 0.85 \\
Type & hydro & steam & steam \\
Speed (r.p.m) & 180 & 3600 & 3600 \\
$\mathrm{X}_{\mathrm{d}}$ & 0.146 & 0.8958 & 1.3125 \\
$\mathrm{X}_{\mathrm{d}}^{\prime}$ & 0.0608 & 0.1198 & 0.1813 \\
$\mathrm{X}_{\mathrm{q}}$ & 0.0969 & 0.8645 & 1.2578 \\
$\mathrm{X}_{\mathrm{q}}^{\prime}$ & 0.0969 & 0.1969 & 0.25 \\
$\tau_{\mathrm{do}}^{\prime}$ & 8.96 & 6 & 5.89 \\
$\tau_{\mathrm{qo}}^{\prime}$ & 0.0 & 0.535 & 0.6978 \\
$\mathrm{~K}_{\mathrm{A}}$ & 100 & 25 & 25 \\
$\mathrm{~T}_{\mathrm{A}}$ & 0.02 & 0.2 & 0.2 \\
$\mathrm{~K}_{\mathrm{f}}$ & 0.01 & 0.091 & 0.108 \\
$\mathrm{~T}_{\mathrm{f}}$ & 0.01 & 0.35 & 0.35 \\
\hline
\end{tabular}

\section{Loads :}

The equivalent shunt admittances for the loads are given in p.u. as :

$$
\begin{aligned}
& \text { Load A }=1.26-\mathrm{j} 0.5044 \\
& \text { Load B }=0.8777-\mathrm{j} 0.2926 \\
& \text { Load C }=0.969-\mathrm{j} 0.3391
\end{aligned}
$$

\section{Transmission Lines :}

The impedances of the tie-lines shown in Fig. 1 are as follows :

\begin{tabular}{|c|c|}
\hline Node No. & Impedance (p.u.) \\
\hline $4-5$ & $0.0100+\mathrm{j} 0.0850$ \\
$4-6$ & $0.0170+\mathrm{j} 0.0920$ \\
$5-7$ & $0.0320+\mathrm{j} 0.1610$ \\
$6-8$ & $0.0390+\mathrm{j} 0.1700$ \\
$7-8$ & $0.0085+\mathrm{j} 0.0720$ \\
$8-9$ & $0.0119+\mathrm{j} 0.1008$ \\
\hline
\end{tabular}




\section{Excitation System :}

The parameters of the excitation system are :

Regulator amplifier gain $=\mathrm{K}_{\mathrm{A}}=25 \mathrm{pu}$

Regulator amplifier time constant $=\mathrm{T}_{\mathrm{A}}=0.05 \mathrm{Sec}$.

Regulator stabilizing circuit gain $=\mathrm{K}_{\mathrm{f}}=0.004 \mathrm{pu}$

Regulator stabilizing circuit time constant $=\mathrm{T}_{\mathrm{f}}=0.04 \mathrm{Sec}$.

Limiter maximum voltage level $=\mathrm{V}_{\max }=1.25 \mathrm{pu}$

Limiter minimum voltage level $=\mathrm{V}_{\min }=-1.25 \mathrm{pu}$

\section{3- Proposed PSS Design :}

The block diagram of the controlled process, exciter and the proposed PSS is shown in Fig.2.

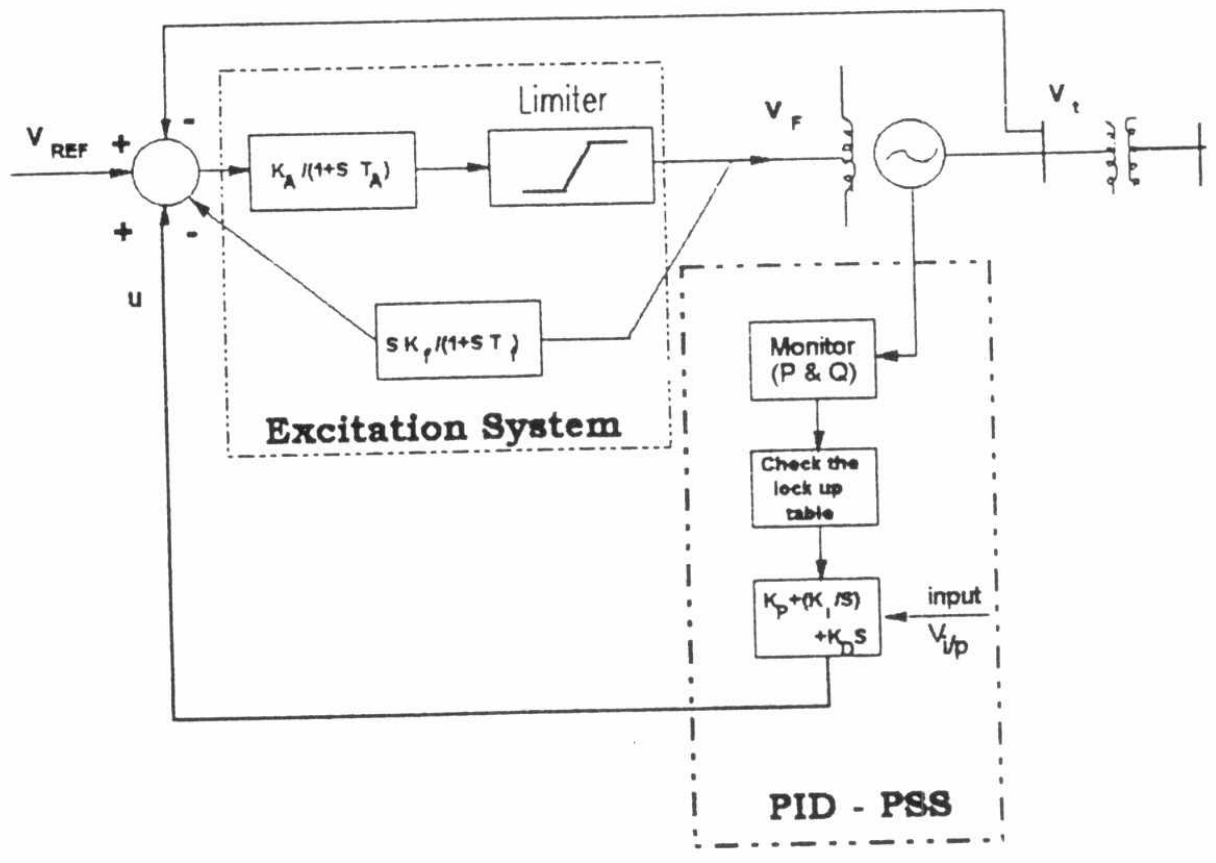

Fig.2 Synchronous machine, exciter, voltage regulator and proposed PID - PSS

The power system under consideration is described by the state-space equations :

$$
\begin{aligned}
& \dot{X}(t)=A \cdot X(t)+B \cdot u(t) \\
& Y(t)=C \cdot X(t)
\end{aligned}
$$


where

$\mathrm{X}^{\mathrm{t}}=\left[\begin{array}{llll}\mathrm{E}_{\mathrm{d}}^{\prime} & \mathrm{E}_{\mathrm{q}}^{\prime} & \omega & \delta\end{array}\right]$ is the state vector,

$\mathrm{Y}$ is the output, and

$\mathrm{u}$ is the control.

Taking LAPLACE transform of Eqs.(1), and (2) we get :

$$
\begin{aligned}
& \mathrm{S} \cdot \mathrm{X}(\mathrm{s})=\mathrm{A} \cdot \mathrm{X}(\mathrm{s})+\mathrm{B} \cdot \mathrm{u}(\mathrm{s}) \\
& \mathrm{Y}(\mathrm{s})=\mathrm{C} \cdot \mathrm{X}(\mathrm{s})
\end{aligned}
$$

Eq.(3) can be rewritten as :

$$
\mathrm{X}(\mathrm{s})=(\mathrm{SI}-\mathrm{A})^{-1} \cdot \mathrm{B} \cdot \mathrm{u}(\mathrm{s})
$$

The control signal $\mathrm{u}(\mathrm{s})$ is expressed as :

$$
\begin{aligned}
\mathrm{u}(\mathrm{s}) & =\mathrm{H}(\mathrm{s}) \cdot \mathrm{Y}(\mathrm{s}) \\
& =\left[\mathrm{K}_{\mathrm{p}}+\frac{\mathrm{K}_{\mathrm{I}}}{\mathrm{s}}+\mathrm{K}_{\mathrm{D}} \mathrm{S}\right] \cdot \mathrm{Y}(\mathrm{s})
\end{aligned}
$$

From Eqs. (4), (5) and (6) we get :

$$
\mathrm{X}(\mathrm{s})=(\mathrm{SI}-\mathrm{A})^{-1} \cdot \mathrm{B} \cdot \mathrm{H}(\mathrm{s}) \cdot \mathrm{C} \cdot \mathrm{X}(\mathrm{s})
$$

Therefore,

$$
\operatorname{det}\left[\mathrm{I}-(\mathrm{SI}-\mathrm{A})^{-1} \cdot \mathrm{B} \cdot \mathrm{H}(\mathrm{s}) \cdot \mathrm{C}\right]=0
$$

If $\lambda$ is the assigned eigenvalue of the closed-loop system, hence

$$
\operatorname{det}\left[I-(\lambda I-A)^{-1} \cdot B \cdot H(\lambda) \cdot C\right]=0
$$

Therefore,

$$
H(\lambda)=\frac{1}{C \cdot(\lambda I-A)^{-1} \cdot B}=\left[K_{p}+K_{D} S+\frac{K_{I}}{S}\right]
$$

The gain settings $\left(\mathrm{K}_{\mathrm{p}}, \mathrm{K}_{\mathrm{I}}\right.$, and $\left.\mathrm{K}_{\mathrm{D}}\right)$ are computed by assigning three prescribed eigen-values of the system. These assigned eigenvalues are substituted 
in Eq.(10). Therefore, three algebraic equations in the three unknowns $\mathrm{K}_{\mathrm{p}}, \mathrm{K}_{\mathrm{I}}$, and $\mathrm{K}_{\mathrm{D}}$ are obtained. So, the gain settings $\left(\mathrm{K}_{\mathrm{p}}, \mathrm{K}_{\mathrm{I}}\right.$, and $\left.\mathrm{K}_{\mathrm{D}}\right)$ are computed by solving these equations. The computation process of the gain settings $\left(\mathrm{K}_{\mathrm{p}}, \mathrm{K}_{\mathrm{I}}\right.$, and $\left.\mathrm{K}_{\mathrm{D}}\right)$ is repeated for other operating conditions. The obtained results from these computations are stored in computer memory together with the corresponding values of the system operating conditions. During on-line operation, the controller tracks the system operating conditions at each sampling period and selects the corresponding set of controller gains $\left(\mathrm{K}_{\mathrm{p}}, \mathrm{K}_{\mathrm{I}}\right.$, and $\left.\mathrm{K}_{\mathrm{D}}\right)$ from the stored data in computer memory. hence, the controller gains are updated according the system operating conditions.

The input signal to the PSS is expressed as :

$$
\mathrm{V}_{\mathrm{i}}=\mathrm{w}_{1} \dot{\delta}+\mathrm{w}_{2} \Delta \mathrm{P}+\mathrm{w}_{3} \Delta \delta
$$

where

$\mathrm{w}_{1}, \mathrm{w}_{2}$ and $\mathrm{w}_{3}$ are weighting factors of the derivative of power angle, error in the output power and error in power angle.

\section{4- Simulation Results :}

The effectiveness of the proposed PSS is investigated when the multimachine system is subjected to different types of disturbances. A three phase short circuit of duration four cycle at bus 7 is considered. Figs. 3 and 4, represent the power system transient response as indicated by the terminal voltage and rotor speed of each machine following the abovementioned disturbance. Investigation of these figures shows that the response of the synchronous generator is improved when it is equipped with the proposed PSS. A further improvement is obtained when the input to the stabilizer combines signals from error in rotor speed, error in output power and error in power angle.

\section{5- Conclusion :}

A method for auto tuning of PID-PSS using a look-up table is proposed in this paper. The application of the proposed PSS to a multimachine power system proves its effectiveness in damping the system oscillations following different types of disturbances. The results obtained from this study indicate that the system response is higly improved with the proposed stabilizer in comparison with the conventional lead-lag PSS. Implementation of this control technique for real-time 
control of a power system using microprocessors is easy to be done and it is left as a future work of this research.

\section{Nomenclature :}

$\begin{array}{ll}\mathrm{E}_{\mathrm{d}}^{\prime}, \mathrm{E}_{\mathrm{q}}^{\prime} & \mathrm{d} \text { and q- components of voltage behind transient reactance } \\ \mathrm{E}_{\mathrm{fD}} & \text { air gap line-open circuit voltage } \\ \mathrm{H} & \text { inertia constant } \\ \mathrm{I}_{\mathrm{d}}, \mathrm{I}_{\mathrm{q}} & \mathrm{d} \text { and q-axis current } \\ \mathrm{K}_{\mathrm{A}} & \text { regulator gain } \\ \mathrm{K}_{\mathrm{P}}, \mathrm{K}_{\mathrm{I}}, \mathrm{K}_{\mathrm{D}} & \text { proportional, integral and derivative gains of PID controller } \\ \mathrm{K}_{\mathrm{F}} & \text { stabilizing transformer gain } \\ \mathrm{P} & \text { active power } \\ \mathrm{T}_{\mathrm{A}} & \text { regulator time constant } \\ \mathrm{T}_{\mathrm{e}} & \text { electrical torque } \\ \mathrm{T}_{\mathrm{F}} & \text { stabilizing transformer time constant } \\ \mathrm{T}_{\mathrm{m}} & \text { mechanical torque } \\ \mathrm{V}_{\mathrm{i}} & \text { input signal to PSS } \\ \mathrm{V}_{\mathrm{S}} & \text { stabilizing transformer voltage } \\ \mathrm{u} & \text { output signal of PSS } \\ \mathrm{X}_{\mathrm{d}}, \mathrm{X}_{\mathrm{q}} & \mathrm{d} \text { and q-axis stator reactances, respectively } \\ \mathrm{X}_{\mathrm{d}}^{\prime}, \mathrm{X}_{\mathrm{q}}^{\prime} & \text { d and q-axis transient stator reactances, respectively } \\ \Delta \mathrm{V} & \text { voltage error signal } \\ \Delta \omega & \text { rotor speed error signal } \\ \delta & \text { power angle } \\ \tau_{\mathrm{do}}^{\prime}, \tau_{\mathrm{qo}}^{\prime} & \mathrm{d} \text { and q-axis transient open circuit time constant } \\ \omega & \text { rotor speed }\end{array}$

\section{References :}

[1] F.P. De Mello, P.J. Nolan, T.F. Laskowski, and J.M. Undrill, "Coordinated application of stabilizers in multimachine power systems", IEEE Trans. PAS, Vol.99, pp. 892-901, 1980.

[2] E.V. Larsen, and D.A. Swann. "Applying power system stabilizers", IEEE Trans. PAS, Vol.100, pp. 3017-3064, 1981.

[3] P.M. Anderson, and A.A. Fouad. "Power system control and stability", Iowa state university press, Iowa, 1977 
[4] D.W. Clarke, and P.J. Gawthrop, "Self-tuning controller", Proc. IEE, Vol.122, No.9, pp. 929-934, 1974.

[5] P.E. Wellstead, J.M. Edmunds, D. Prager, and Zanker, "Self-Tuning pole/zero assignment regulators", IN.J. control, Vol.30, No.1, pp. 1-26, 1979.

[6] S.J. Cheng, O.P. Malik, and G.S. Hope, "Damping of multi-model oscillations in power systems using a dual-rate adaptive stabilizer", IEEE Trans. on power systems, Vol.3, No.1, pp. 101-108, feb.1988.

[7] C.J. Wu, and Y.Y. Hsu, "Design of self-tuning PID power system stablizer for multimachine power systems", IEEE Trans. on power systems, Vol.3, No.3, Aug. 1988.

[8] M. Zhaung, and O.P. Atherton, "Automatic tuning of optimum PID controllers", IEE Proc., Vol. 140, Pt. D, No.3, pp.216-224, May 1993.

\section{Appendix A}

\section{Synchronous machine Equations :}

The synchronous generator is simulated by the two axis model [3]. Therefore, it is represented by a set of four differential equations as :

$$
\begin{aligned}
& \tau_{\mathrm{qo}}^{\prime} \cdot \dot{\mathrm{E}}_{\mathrm{d}}^{\prime}=-\mathrm{E}_{\mathrm{d}}^{\prime}-\left(\mathrm{X}_{\mathrm{q}}-\mathrm{X}_{\mathrm{q}}^{\prime}\right) \mathrm{I}_{\mathrm{q}} \\
& \dot{\mathrm{E}}_{\mathrm{q}}^{\prime}=\frac{1}{\tau_{\mathrm{do}}^{\prime}}\left(\mathrm{E}_{\mathrm{fD}}-\mathrm{E}\right) \\
& \tau_{\mathrm{j}} \cdot \dot{\omega}=\mathrm{T}_{\mathrm{m}}-\mathrm{T}_{\mathrm{e}}
\end{aligned}
$$

where

$$
\begin{gathered}
T_{e}=E_{d}^{\prime} \cdot I_{d}+E_{q}^{\prime} \cdot I_{q}-\left(L_{q}^{\prime}-L_{d}^{\prime}\right) I_{d} \cdot I_{q} \\
\dot{\delta}=\omega-1
\end{gathered}
$$

\section{Excitation System :}

Referring to Fig.2, the mathematical model of the excitation system may be expressed as [3] :

$$
\begin{aligned}
& \dot{\mathrm{E}}_{\mathrm{fD}}=\frac{1}{\mathrm{~T}_{\mathrm{A}}}\left[\mathrm{K}_{\mathrm{A}}\left(\Delta \mathrm{V}+\mathrm{V}_{\mathrm{SS}}-\mathrm{V}_{\mathrm{S}}\right)-\mathrm{E}_{\mathrm{fD}}\right] \\
& \dot{\mathrm{V}}_{\mathrm{s}}=\frac{1}{\mathrm{~T}_{\mathrm{A}} \cdot \mathrm{T}_{\mathrm{f}}}\left[\mathrm{K}_{\mathrm{A}} \cdot \mathrm{K}_{\mathrm{f}}\left(\Delta \mathrm{V}+\mathrm{V}_{\mathrm{SS}}-\mathrm{V}_{\mathrm{s}}\right)-\mathrm{K}_{\mathrm{f}} \cdot \mathrm{E}_{\mathrm{fD}}\right]-\frac{\mathrm{V}_{\mathrm{s}}}{\mathrm{T}_{\mathrm{f}}}
\end{aligned}
$$




\begin{tabular}{|l|l|}
\hline$G C-5$ & 65 \\
\hline
\end{tabular}
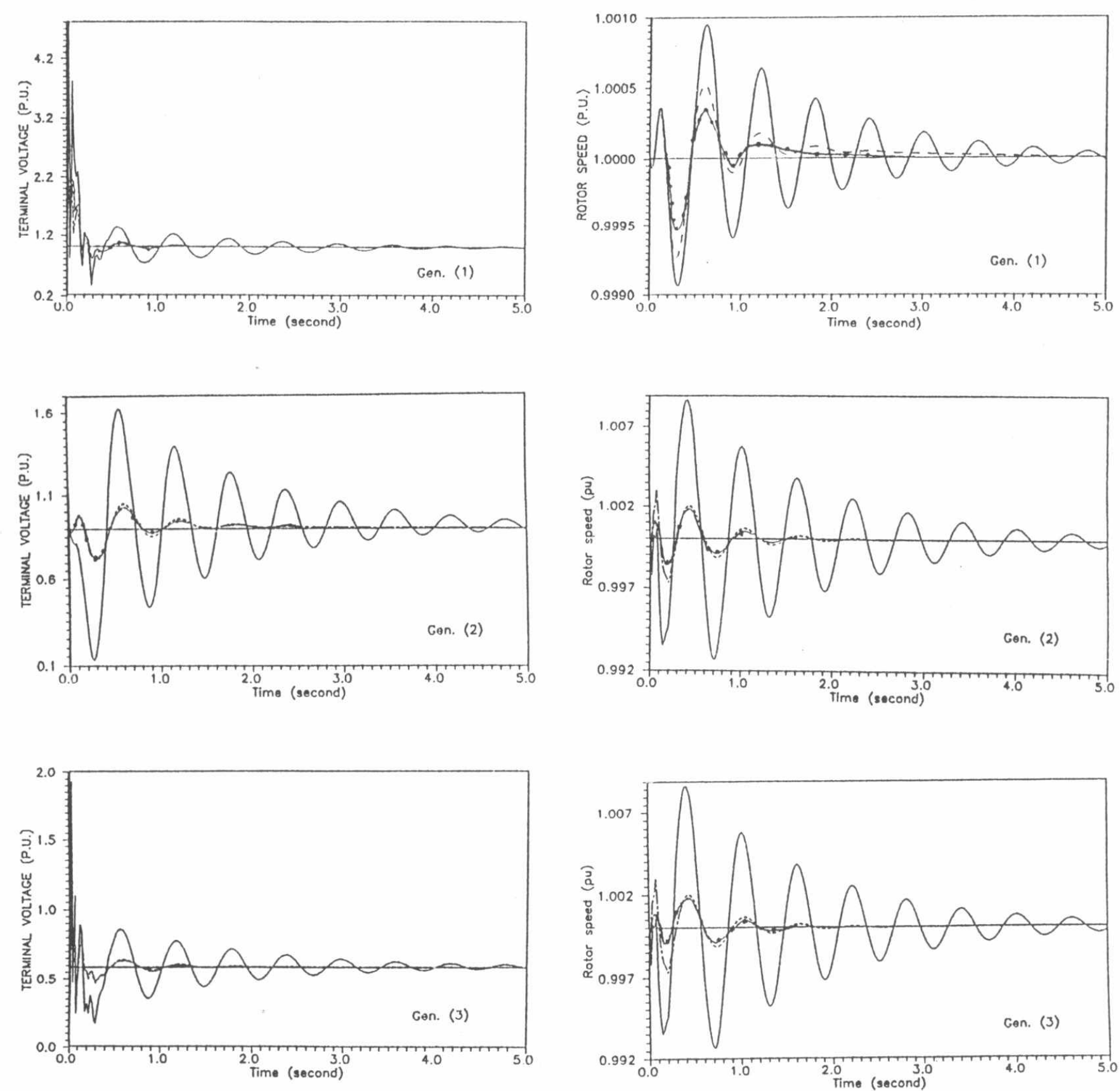

Fig.(3) Terminal Voltage/time curves

2 - 4 MaY 1995, CAIRO
SIXTH ASAT CONFERENCE 